\title{
Effect of Build Orientation on Mechanical Behaviour and Build Time of FDM 3D-Printed PLA Parts: An Experimental Investigation
}

\author{
Meltem Eryildiz ${ }^{1 *}$ \\ 'Department of Mechanical Engineering, Faculty of Engineering and Architecture, Beykent University, Istanbul,34398, Turkey
}

\begin{abstract}
One of the important process parameters affecting the tensile strength and build time of the part is the build orientation. Therefore, in this study, FDM 3D-printed PLA parts were fabricated at different build orientations to examine the effects of build orientation on the tensile properties and build time of material. In this regard, three build orientations and three print angles were examined. According to results, tensile strength decreased when the build orientation of the parts was aligned from flat to upright direction and $0^{\circ}$ to $90^{\circ}$ printing angle. For upright build orientation, 36\% less tensile strength was obtained compared to the flat ones because of the fracture mode and the loading direction. In terms of build time, build time increased as the build orientation changed from flat to upright. Therefore, the build orientation had a big impact on the tensile properties and build time of the parts produced using FDM. The findings of this study will contribute to the literature on proper build orientations and print angles.
\end{abstract}

Keywords: Fused deposition modeling, 3D printing, build orientation, build time, tensile strength, PLA

\section{INTRODUCTION}

Additive manufacturing (AM) creates 3D parts by adding layer-upon-layer of material for a wide variety of industrial and other applications. Contrary to the traditional production technique in which the material is removed until the desired part is obtained, AM is used in variety applications in defense, aircraft, medical, automobile industries etc. There are many different AM techniques, including Stereolithography (SLA), Selective Laser Sintering (SLS) or Laminated Object Manufacturing (LOM), etc. Among these AM techniques, Fused Deposition Modeling (FDM) stands out and is frequently used around the world [1-3]. A wide variety of materials are available in the FDM technique which has low maintenance cost, low fabrication cost even for complex parts and is environmentally friendly [4]. G-codes files are generated directly from CAD files, usually in STL format. In this technique, parts are produced by adding layer upon layer of material until the shape of the part is formed. Filament is heated to a semi-liquid state and G-code controls the movement of the nozzle as shown in Figure $1[5,6]$.

Many process parameters in FDM have great influence on the component properties and production efficiencies. Layer thickness, raster angle, build orientation, infill density, printing speed, infill pattern, raster width, etc. can be listed as some of the important process parameters. Researchers are still working hard to obtain the best parameter settings. Therefore, in order to improve the mechanical properties of the printed parts by setting optimal process parameters, the FDM process needs to be studied more intensively $[1,6]$. Build orientation shows how the part is positioned relative to the three major axes of the 3D printer [6]. For instance, Feng et al. [7] fabricated PA12 (polyamide 12), and Corapi et al. [8] fabricated FDM 3D-printed PLA ((polylactide acid) parts in different directions. Moreover, Ashtankar et al. [9] showed the effect of build orientation of FDM 3D-printed ABS (Acrylonitrile Butadiene Styrene) parts and their result indicated that the compressive strength and tensile strength decreased when the orientation of the samples was aligned from $0^{\circ}$ to $90^{\circ}$. Thrimurthulu et al. [10] studied optimum build orientation in FDM. Durgun and Ertan [11] demonstrated that the samples built with $0^{\circ}$ raster angle in the horizontal direction had best mechanical properties and surface roughness with the optimal build time and cost. Thus, it has been observed that, the build orientation for the parts produced using the FDM method has a great effect on the mechanical properties of the part [12]. Also, the printing angle affects the mechanical properties of the FDM 3D-printed parts because it affects the anisotropy [13]. 


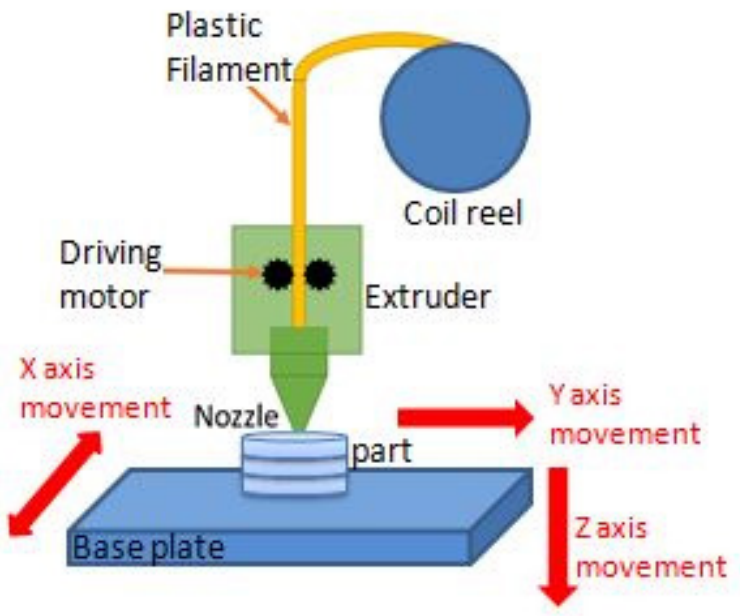

Figure 1. FDM process schematic [6]

Aim of this study is to investigate the influence of build orientation on the tensile properties and build time. The effects of flat and upright build orientations and flat printing angles on the tensile strength and build time of FDM parts were examined in this context. In this study, PLA (polylactide acid) was used due to its interesting properties in terms of non-toxicity, biodegradability and ease of processing. In order to analyze the impacts of build orientation on the tensile behavior and build time of the material, three build orientations and three print angles were examined.

\section{EXPERIMENTAL METHODS}

Commercial Polylactic acid (PLA) filament with a $1.75 \mathrm{~mm}$ diameter was used on a 3D Printing machine, Creality ender
$3 \mathrm{~d}$ pro (Figure 2). The nozzle diameter was $0.4 \mathrm{~mm}$. The data of the specimens were all in STL format and then translated into G-code sliced with slic3r. Slic3r is an open source slicer software. In this study, specimens for each direction (flat, on edge, upright, and flat $-0^{\circ}, 45^{\circ}, 90^{\circ}$ angle-, Figure 3 ) and have been printed for the tensile test. The process parameters not only affect the mechanical strength of the parts but also the build time.

The parts were fabricated under the American Society

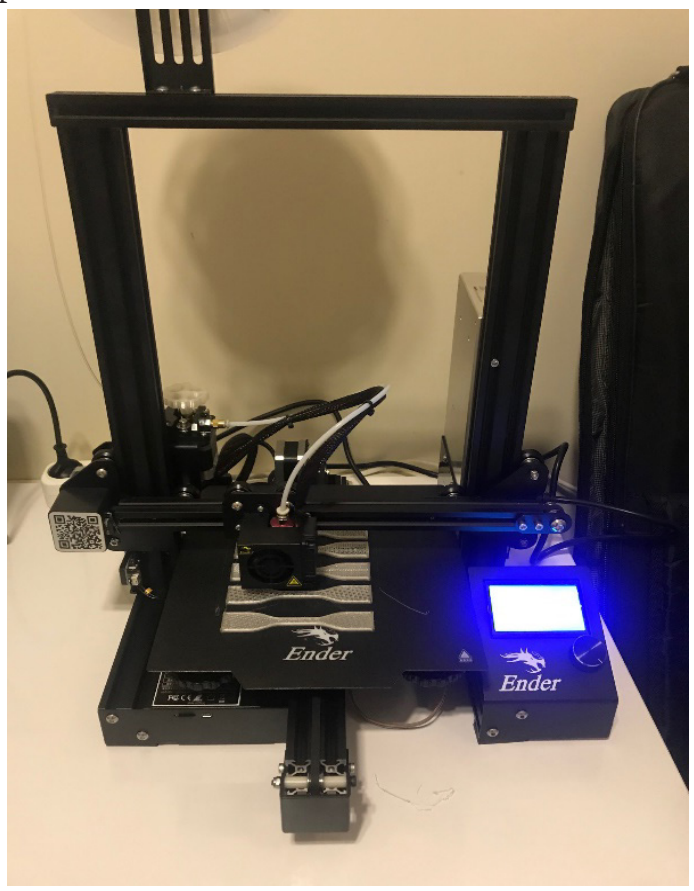

Figure 2. Ender 3 pro 3D printer

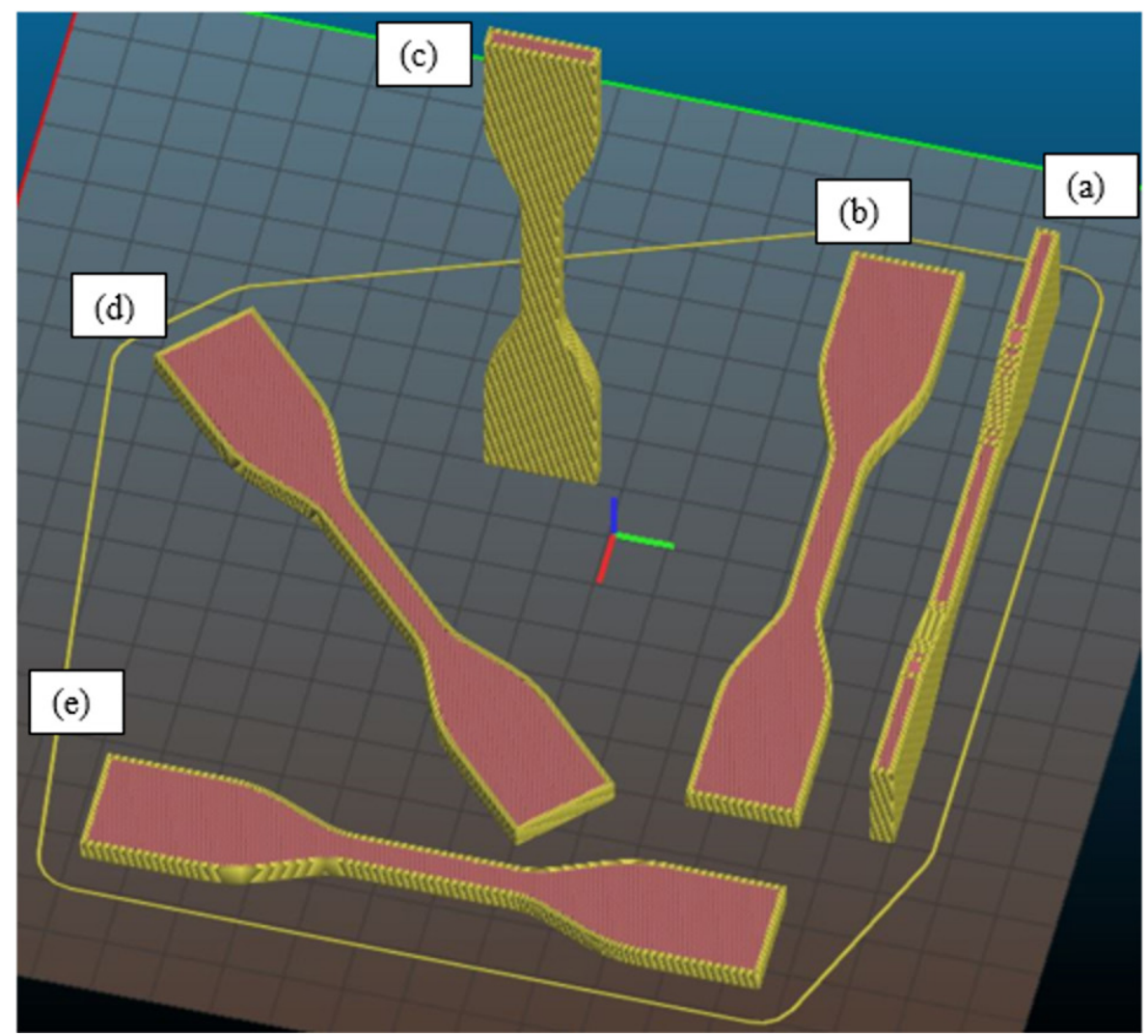

Figure 3. Tensile specimen oriented in various build orientations (a) on edge, b) flat $0^{\circ}$, (c) upright, (d) flat $45^{\circ}$, (e) flat $90^{\circ}$ 
for Testing and Materials (ASTM) standard D638 type IV shown in the Figure 4. The dog bone type parts were built according to the process parameters given in Table 1.

Table 1. Parameters of printer settings.

\begin{tabular}{|c|c|}
\hline Table 1. Parameters of printer settings. \\
\hline Items & Value \\
\hline Nozzle diameter [mm] & 0.4 \\
\hline Wall thickness [mm] & 0.8 \\
\hline Layer height [mm] & 0.2 \\
\hline Wall line count & 3 \\
\hline Infill Density [\%] & 30 \\
\hline Printing Temperature [C] & 200 \\
\hline Build Plate Temperature [C] & 60 \\
\hline Print Speed [mm/s] & 60 \\
\hline
\end{tabular}

The tensile tests are performed on universal testing machines (Instron 8872) with a load cell of $25 \mathrm{kN}$ at room temperature (Figure 5). The test speed was $1 \mathrm{~mm} / \mathrm{min}$.

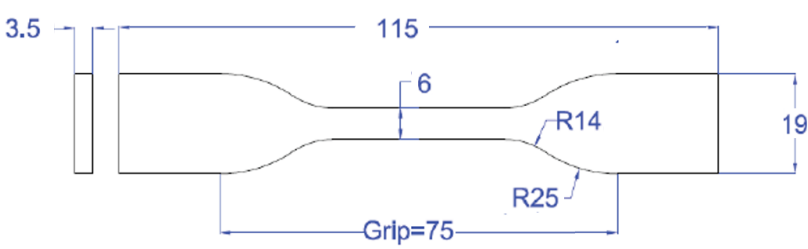

Figure 4. CAD model of the specimen, dimensions in $\mathrm{mm}$

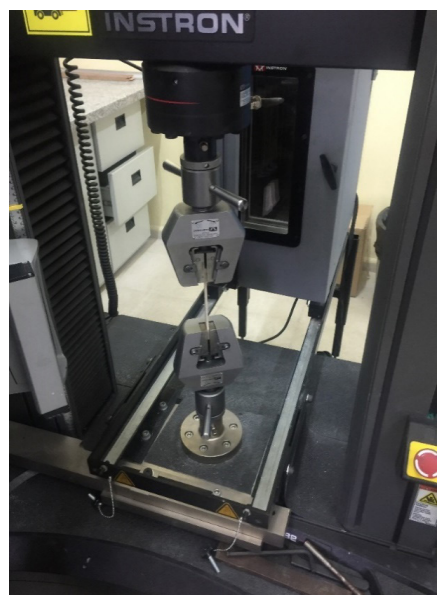

Figure 5. Tensile test setup

\section{RESULTS AND DISCUSSION}

The tensile strength, filament spent and build time of the samples are listed in Table 2. The stress-strain curves of samples printed in different orientations are plotted in Figure 6. Build time was taken by the machine to fabricate the parts.

Table 2. The tensile strength, filament spent and build time of the samples

\begin{tabular}{|c|c|c|c|}
\hline & $\begin{array}{c}\text { Build Time } \\
{[\mathrm{min}]}\end{array}$ & $\begin{array}{c}\text { Filament Spent } \\
{[\mathrm{mm}]}\end{array}$ & $\begin{array}{c}\text { Tensile Strength } \\
{[\mathrm{MPa}]}\end{array}$ \\
\hline (a) on edge & 59 & 1846.5 & 48.18 \\
\hline (b) flat $0^{\circ}$ & 29 & 1231.4 & 55.49 \\
\hline (c) upright & 231 & 2037.2 & 35.52 \\
\hline (d) flat $45^{\circ}$ & 29 & 1207.9 & 53.47 \\
\hline (e) flat $90^{\circ}$ & 29 & 1231.4 & 51.77 \\
\hline
\end{tabular}

In terms of mechanical properties, it can be seen from Figure 6 and Table 2 that the flat $0^{\circ}$ orientation reaches maximum tensile strength (55.49 MPa), while the upright orientation reaches the minimum $(35.52 \mathrm{MPa})$. Because the tensile

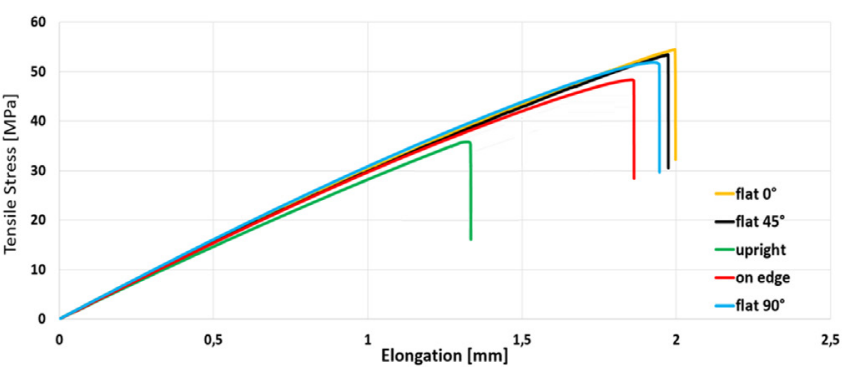

Figure 6. The stress-strain curves of the samples at different building orientations

strength of FDM 3D-printed PLA parts becomes optimal if the parts are fully oriented along the direction of loading stress [14]. As shown in Figure 7a, the parts that can transfer the stress at the highest level are the parts oriented along the loading stress direction. And, as shown in Figure 7b, fracture mode of the upright build orientation differs from the flat build orientation. There are two types of fracture modes which are the interlayer fracture and the intra-layer fracture and the fracture mode affects the mechanical strength of the FDM 3D-printed PLA parts. The interlayer fracture strength mainly depends on the interlayer bonding strength, and the intra-layer fracture mainly depends on the strength of the extruded material [13]. Obviously, the loading direction of the upright build oriented part is totally perpendicular to the direction of the extruded lines, indicating that the bond between line and line is weak and that interlayer fracture occurs easily during the tensile test $[8,14]$. According to the tensile results listed in Table 2, samples printed in horizontal directions exhibited higher tensile strength, while samples printed in vertical (upright) direction exhibited 36\% lower tensile strength.

In terms of print angles, it was seen that the mechanical properties and build time of the flat $0^{\circ}$, flat $45^{\circ}$, flat $90^{\circ}$ parts were not much different (Figure 6 and Table 2). The print

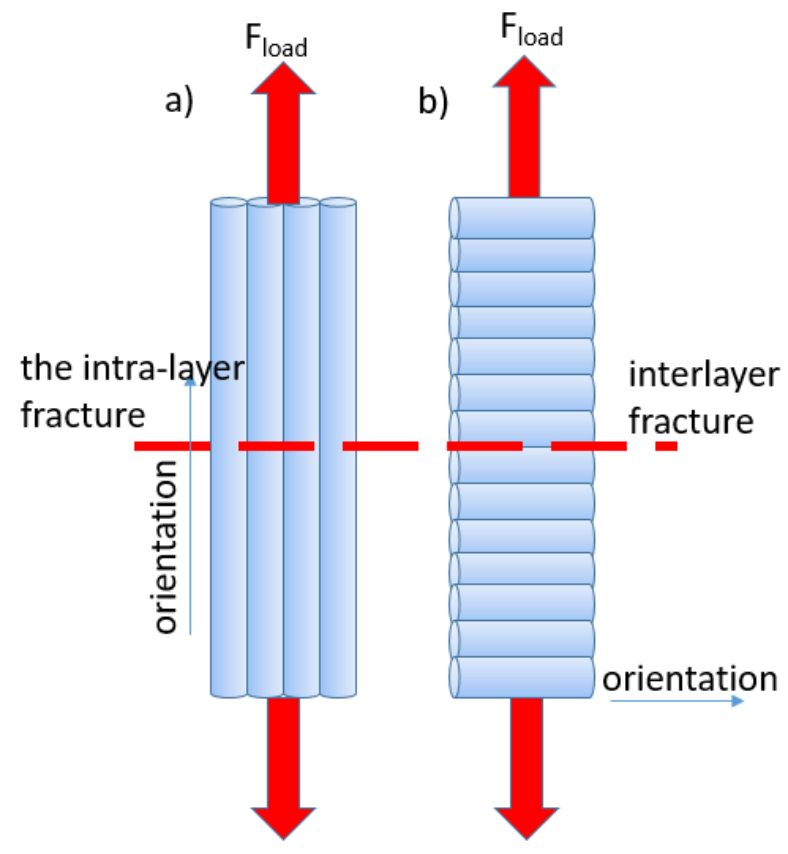

Figure 7. Tensile failure mechanism at (a) flat (horizontal), (b) upright (vertical) orientation 
angles can be seen in Figure 8. It has been observed that, the $0^{\circ}$ angle had the maximum tensile strength, followed by the $45^{\circ}$, and $90^{\circ}$ printing angles, respectively. The tensile strength for the $0^{\circ}, 45^{\circ}$, and $90^{\circ}$ printing angles were 55.49 $\mathrm{MPa}$, 53.47 $\mathrm{MPa}$, and $51.77 \mathrm{MPa}$, respectively. The reason the $0^{\circ}$ printing angle had the highest mechanical properties was that the orientation of the structure aligned with the direction of the loading force in a single slice of the original filament. Thus, the direction of the loading should be considered when designing and applying the FDM 3D-printed PLA parts [15].
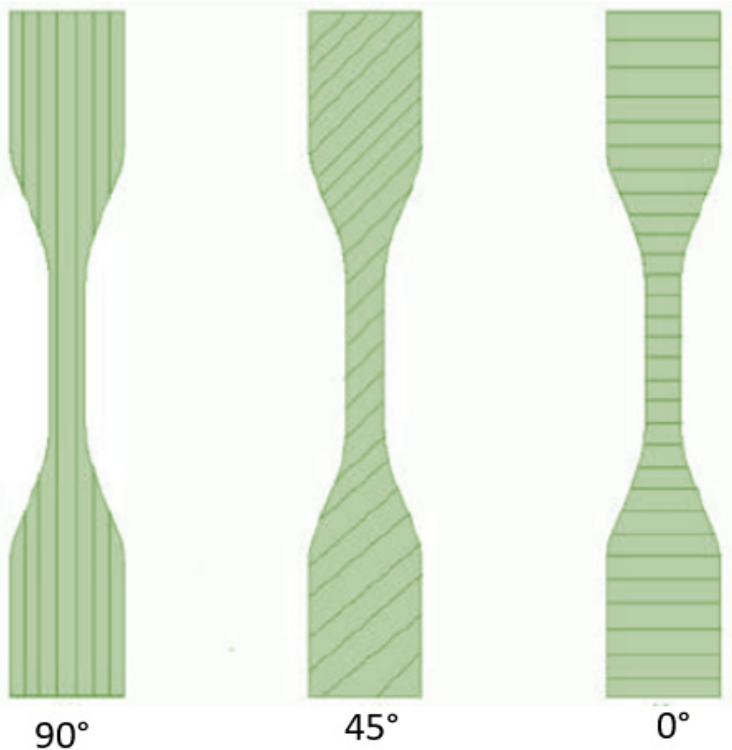

Figure 8 . Schematic representation of the printed direction in each slice

From the standpoint of build time, as the build orientation changed from flat to upright, the build time increased. At the upright build orientation, the required build time increased because the number of layers for this build orientation was much higher. Furthermore, it has been known that when the build time becomes longer and higher amount of material is used, energy usage increases and this leads to higher energy costs [16]. Thus, FDM 3D-printed PLA parts can be manufactured with good mechanical properties with minimal build time at the flat build orientation.

\section{CONCLUSIONS}

FDM 3D-printed PLA parts were fabricated at different build orientations to examine the effects of build orientation on the tensile properties and build time of the material. In this regard, three build orientations and three print angles were examined. According to results, tensile strength decreased when the build orientation of the parts was aligned from flat to upright direction and $0^{\circ}$ to $90^{\circ}$ printing angle. For upright build orientation, 36\% less tensile strength was obtained compared to the flat ones because of the fracture mode and the loading direction. It is thus revealed that the build orientation had a big impact on the mechanical properties and build time of the FDM 3D-printed PLA parts. The build orientation and the direction of the loading must be considered in terms of mechanical properties and man- ufacturing cost, when designing and applying the FDM 3D-printed PLA parts.

\section{RERERENCES}

[1] Altan, M., Eryildiz, M., Gumus, B., Kahraman, Y. (2018). Effects of process parameters on the quality of PLA products fabricated by fused deposition modeling (FDM): surface roughness and tensile strength. Materials Testing, 60(5): 471-477, DOI: 10.3139/120.111178

[2] Srinivasan, R., Ruban, W., Deepanraj, A., Bhuvanesh, R., Bhuvanesh, T. (2020). Effect on infill density on mechanical properties of PETG part fabricated by fused deposition modelling. Materials Today: Proceedings, 27(2):1838-1842, DOI: 10.1016/j.matpr.2020.03.797

[3] Bardiya, S., Jerald, J., Satheeshkumar, V. (2020). Effect of process parameters on the impact strength of fused filament fabricated (FFF) polylactic acid (PLA) parts. Materials Today: Proceedings, DOl: 10.1016/j.matpr.2020.08.066

[4] Garg, A., Bhattacharya, A., Batish, A. (2015). On Surface Finish and Dimensional Accuracy of FDM Parts after Cold Vapor Treatment. Materials and Manufacturing Processes, 31(4): 522-529, DOI: 10.1080/10426914.2015.1070425

[5] Alafaghani, A., Qattawi, A., Alrawi, B., Guzman, A. (2017). Experimental Optimization of Fused Deposition Modelling Processing Parameters: A Design-for-Manufacturing Approach. Procedia Manufacturing, 10: 791-803, DOI: 10.1016/j.promfg.2017.07.079

[6] Solomon, I.J., Sevvel, P., Gunasekaran, J. (in press). A review on the various processing parameters in FDM. Materials Today: Proceedings, DOI: 10.1016/j.matpr.2020.05.484

[7] Feng, L., Wang, Y., Wei, Q. (2019). PA12 Powder Recycled from SLS for FDM. Polymers, 11: 727-729, DOI: 10.3390/polym11040727

[8] Corapi, D., Morettini, G., Pascoletti, G.,Zitelli, C. (2019). Characterization of a Polylactic acid (PLA) produced by Fused Deposition Modeling (FDM) technology. Procedia Structural Integrity, 24: 289295, DOI: 10.1016/j.prostr.2020.02.026

[9] Ashtankar, K.M., Kuthe, A.M., Rathour, B.S. (2013). Effect of build orientation on mechanical properties of rapid prototyping (Fused Deposition Modeling) made Acrylonitrile Butadiene Styrene (ABS) Parts. ASME 2013 International Mechanical Engineering Congress and Exposition, 11: 1-7, DOI: 10.1115/IMECE2013-63146

[10] Thrimurthulu, K., Pandey, P., Reddy, N.V. (2004). Optimum Part Deposition Orientation in Fused Deposition Modelling. International Journal of Machine Tools, 44: 585-594, DOI: 10.1016/j.jimachtools.2003.12.004

[11] Durgun, I., Ertan, R. (2014). Experimental Investigation of FDM Process for Improvement of Mechanical Properties and Production Cost. Rapid prototyping, 20(3): 228-235, DOl: 10.1108/RPJ-102012-0091

[12] Chaudhari, M., Jogi, B.F., Pawade, R.S. (2018). Comparative Study of Part Characteristics Built Using Additive Manufacturing (FDM). Procedia Manuf, 20: 73-78, DOI: 10.1016/.jpromfg.2018.02.010.

[13] Wang, S., Ma, Y., Deng, Z., Zhang, S., Cai, J. (2020). Effects of fused deposition modeling process parameters on tensile, dynamic mechanical properties of 3D printed polylactic acid materials. Polymer testing, 86: 106483, DOI: 10.1016/j.polymertesting.2020.106483

[14] Liu, H., He, H., Peng, X., Huang, B., Li, J. (2019). Three-dimensional printing of poly(lactic acid) bio-based composites with sugarcane bagasse fiber: Effect of printing orientation on tensile performance. Advances in Polymer Technology, 30: 910- 922, DOI: 10.1002/ pat. 4524 
[15] Cai, L., Byrd, P., Zhang, H., Schlarman, K., Zhang, Y., Golub, M., Zhang, J. (2016). Effect of Printing Orientation on Strength of 3D Printed ABS Plastics. The Minerals, Metals \& Materials Society. (Eds.), TMS 2016 145th Annual Meeting \& Exhibition. Springer, Cham, p. 199204.

[16] Jiang, J., Xu, X., Stringer, X. (2018). Support Structures for Additive Manufacturing: A Review, Journal of Manufacturing and Materials Processing, 2(64): 1-23, DOI: 10.3390/jmmp2040064 